G. PUPO, F. IBBA, D. M. H. ASCOUGH, A. C. VICINI, P. RICCI, K. E. CHRISTENSEN,

L. PFEIFER, J. R. MORPHY, J. M. BROWN, R. S. PATON, V. GOUVERNEUR* (UNIVERSITY OF OXFORD AND ELI LILLY AND CO. LTD., WINDLESHAM, UK)

Asymmetric Nucleophilic Fluorination under Hydrogen Bonding Phase-Transfer Catalysis

Science 2018, 360, 638-642.

\title{
Hydrogen-Bonding Phase-Transfer Catalyst Enabled Asymmetric Fluorination
}

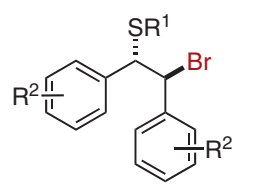

(rac)-1

$\mathrm{R}^{1}=\left(\mathrm{CH}_{2}\right)_{2} \mathrm{Ph}$ or $\mathrm{Me}$

$\mathrm{R}^{2}=$ halide, $\mathrm{Me}$, OMe

Selected examples:

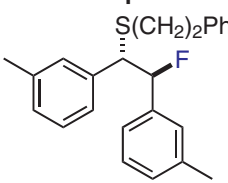

$62 \%$ yield, er $=94: 6$ (gram scale)

.

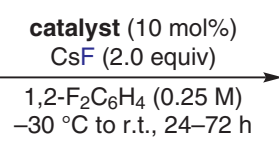

$-30{ }^{\circ} \mathrm{C}$ to r.t., $24-72 \mathrm{~h}$<smiles>CC(CC(c1ccccc1)c1ccc(Cl)cc1)(c1ccccc1)c1ccccc1</smiles>

$53 \%$ yield, er $=93: 7$

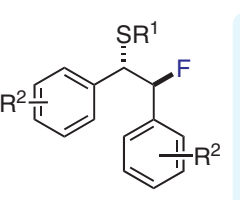

$(S, S)-2$

12 examples

$53-98 \%$ yield er from $91: 9$ to $97: 3$
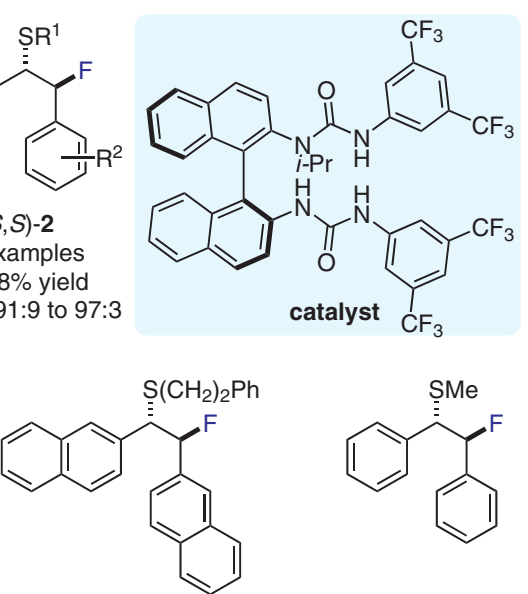

$72 \%$ yield, er $=95.5: 4.5$

$87 \%$ yield, er $=91: 9$

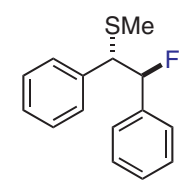

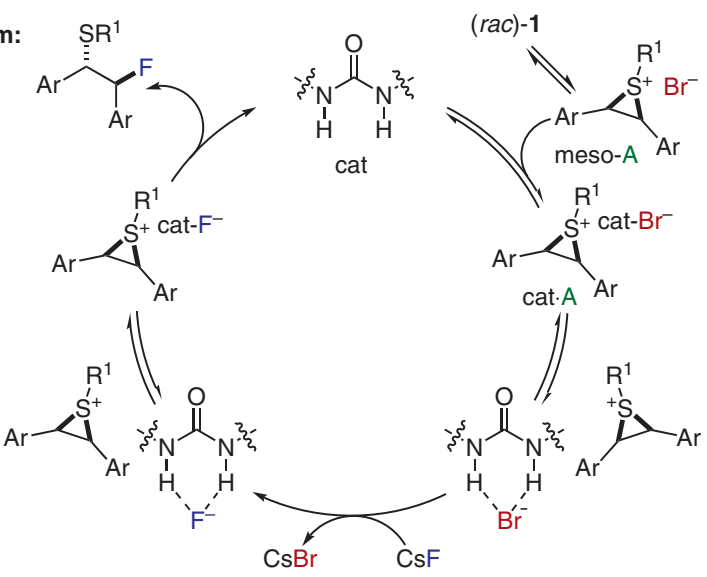

Gategory

Organo- and Biocatalysis

\section{Key words}

phase-transfer catalysis

\section{nucleophilic} fluorination

hydrogen bonding

bis-urea catalysis

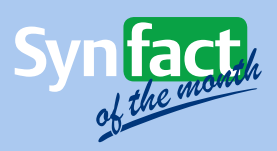

Significance: Gouverneur and co-workers merge two fundamental strategies of modern catalyst design, hydrogen-bonding interactions and phasetransfer catalysis, to report a chiral bis-urea catalyzed asymmetric nucleophilic fluorination of episulfonium salts formed in situ. The fluorinated products are formed in good to excellent yields and moderate to good enantioselectivities by using $\mathrm{CsF}$.

SYNFACTS Contributors: Benjamin List, Jennifer L. Kennemur Synfacts 2018, 14(08), 0861 Published online: 18.07.2018 DOI: 10.1055/s-0037-1609893; Reg-No.: B05418SF
Comment: Hydrogen-bonding phase-transfer catalysis (HB PTC) has been previously reported in highly enantioselective nitro-Mannich reactions (B. Wang, Y. Liu, C. Sun, Z. Wei, J. Cao, D. Liang, Y. Lin, H. Duan Org. Lett. 2014, 16, 6432). Gouverneur and co-workers develop such catalysts to solve a synthetic challenge; namely, to enable an asymmetric fluorination reaction using a safe and readily accessible inorganic fluorine source. Henceforth, the expansion of HB PTC to other systems is expected. 